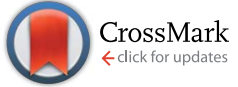

Cite this: RSC Adv., 2017, 7, 218

Received 8th October 2016 Accepted 2nd November 2016

DOI: 10.1039/c6ra24886a

www.rsc.org/advances

\title{
Multistimuli-responsive organogels based on hydrazide and azobenzene derivatives $\dagger$
}

\begin{abstract}
Xiaojun Gu, ${ }^{a}$ Binglian Bai, ${ }^{\star a}$ Haitao Wang ${ }^{\mathrm{b}}$ and Min Li*b
The behaviors of organogels of gelators containing hydrazide and azobenzene units connected via different flexible central spacers, 1-[4-(4'-methoxylphenylazo)phenoxy]-n-[(N-(4-nitrobenzoyl)- $N^{\prime}$ (benzoyl-4'-oxy)hydrazine)]alkane (En, $n=5,6,10)$ have been studied. The length and parity of the central flexible spacer play crucial roles in the gelation. E6 and E10 could form a stable organogel in DMF, and the critical gelation concentration of E10 is higher than that of E6, but no gelation is observed for compound E5. Xerogels of E6 and E10 from DMF exhibited fibrous aggregates. The organogels showed a photoinduced gel-to-precipitate transition under the irradiation by UV light irradiation, which was attributed to the photoisomerization of azobenzene. The trans-cis isomerization in gels further caused the morphological change from fibrous to globular aggregates. In addition, the organogel exhibited multiple stimuli-responsive behaviors upon exposure to stimuli such as temperature, anions and $\mathrm{pH}$.
\end{abstract}

\section{Introduction}

Low molecular weight organogels (LMWGs) which were driven by non-covalent interactions including hydrogen bonds, hydrophobic interactions, $\pi-\pi$ interactions and van der Waals forces have attracted considerable attention as a key class of soft nanostructured material. ${ }^{1-4}$ Recently, numerous efforts have been devoted to the development of stimuli-responsive gels, whose properties can be either switched on-off or tuned in the presence of an external or internal chemical or physical stimulus such as light, ${ }^{5,6} \mathrm{pH},{ }^{7-9}$ ultrasound, ${ }^{10,11}$ or ionic stimuli. ${ }^{12,13}$

Supramolecular organogels and liquid crystals are fascinating organized self-assembled soft materials. ${ }^{14}$ Liquid crystal dimers are composed of molecules containing two conventional mesogenic groups linked via a flexible spacer. These materials show quite different behavior to conventional low molar mass liquid crystals and in particular their transitional behavior exhibits a dramatic dependence on the length and parity of the flexible spacer. ${ }^{15}$ We have reported that the unusual mesophase of liquid crystal dimer En (Scheme 1), ${ }^{\mathbf{1 6}} \mathbf{E 6}$ and E10 exhibit enantiotropic SmA phase, while E5 is nonmesomorphic. In addition, the melting point of E5 is much lower than that of E6, which indicated the characteristic oddeven effect in En. Recently, we reported that the effect of flexible

${ }^{a}$ Key Laboratory of Coherent Light and Atomic and Molecular Spectroscopy of Ministry of Education, College of Physics, Jilin University, Changchun 130012, PR China

${ }^{b}$ Key Laboratory for Automobile Materials (JLU), Ministry of Education, College of Materials Science and Engineering, Jilin University, Changchun 130012, PR China. E-mail:weijue@jlu.edu.cn; minli@mail.jlu.edu.cn; Tel: +86-431-85168254

$\uparrow$ Electronic supplementary information (ESI) available. See DOI: 10.1039/c6ra24886a central spacer on the trans-cis photoisomerization of azobenzene organogels. ${ }^{17}$ However, to date, there is no report of the length and parity of the central flexible spacer effect on the properties of organogels.

Our present paper focused on the gelation behavior, photoresponsive, anion-responsive and $\mathrm{pH}$-responsive behavior of $\mathbf{E n}$ (Scheme 1). The results of these studies contribute to further understanding the structure-property relationships of LMOGs.

\section{Experimental}

\subsection{Characterization}

Xerogels were prepared by freezing and pumping the organogel of E6/E10 for 3 days. Field emission scanning electronicmicroscopy (FE-SEM) observations were recorded with a SSX550 apparatus. X-Ray diffraction (XRD) was carried out on a Bruker Avance E6/E10 X-ray diffractometer. The xerogels were pressed into a tablet with $\mathrm{KBr}$ for the Fourier transform IR spectrum (FTIR) measurements. Differential scanning calorimetry (DSC) curves were obtained on a Netzsch DSC 204 instrument. The UV irradiation was carried out with a $500 \mathrm{~W}$ Xe lamp with bandpass filter (280-375 nm).

${ }^{1} \mathrm{H}-\mathrm{NMR}$ spectra were recorded with a Bruker Avance 500 $\mathrm{MHz}$ spectrometer and Mercury-300BB $300 \mathrm{MHz}$ spectrometer using dimethyl sulfoxide-d as a solvent and tetramethylsilane (TMS) as an internal standard $(\delta=0.00)$. UV-vis absorption spectra were recorded on a Shimadzu UV-2550 spectrometer.

Spectrophotometric titrations were performed on solutions of receptors in DMF at room temperature. Anions $\left(\mathrm{F}^{-}, \mathrm{Cl}^{-}, \mathrm{Br}^{-}\right.$, $\mathrm{I}^{-}$and $\mathrm{AcO}^{-}$) and $\mathrm{NaOH}$ were used in solution by adding the relative alkylammonium salts. 


\section{Results and discussion}

The compounds En were synthesized in our laboratory, and their structures were confirmed by FTIR, ${ }^{1} \mathrm{H}$-NMR spectroscopy and elemental analysis. The synthetic details were reported elsewhere. $^{16}$

\subsection{Gelation behaviors}

The gelation abilities of $\mathbf{E} \boldsymbol{n}$ were evaluated in various organic solvents by the standard heating and cooling method. The compounds En were insoluble in aliphatic hydrocarbon solvents, lower alcohols and aromatic solvents, such as $n$ hexane, cyclohexane, chloroform, methanol and toluene by heating, but were easily dissolved in $N, N$-dimethylformamide (DMF), dimethyl sulfoxide (DMSO) and tetrahydrofuran (THF). E6 and E10 could form stable organogel in DMF, and the critical gelation concentrations (CGC) of E10 $\left(11.5 \mathrm{mg} \mathrm{mL}^{-1}\right)$ is higher than that of E6 ( $\left.8 \mathrm{mg} \mathrm{mL}^{-1}\right)$, it indicates that $\mathbf{E 6}$ gelation is more efficient than E10, but no gelation is observed for compound $\mathbf{E 5}$ (Table S1 $\dagger$ ). This behavior may be most attributed to the dependence of the molecular shape on the parity of the spacer considered in the all-trans conformation. In E6, with an even numbered spacer (Fig. S1a $\dagger$ ), the molecules are disposed to give an overall rodlike shape, whereas in $\mathbf{E 5}$, with an odd-numbered spacer (Fig. S1b $\dagger$ ), the molecules are inclined with respect to each other giving a bent-shaped motif. The structure of E6 with even-numbered spacer is considered to be more compatible with the molecular organization. ${ }^{15}$ Meanwhile, the dipole moment value of E5 with bent-shaped motif increases, which improves the solubility of the E5 in DMF (polar solvent) and thus disturbs the aggregation of the E5 molecules, so the increase of the dipole moment value may be another reason for the gelation behavior. Fig. S2 $\uparrow$ shows the gel-sol transition temperature ( $T_{\text {gel }}$ ) of the E6 and E10 gels in DMF as a function of concentration.
The aggregation morphologies of $\mathbf{E} \boldsymbol{n}$ were investigated by scanning electron microscopy (SEM). As shown in Fig. 1, the E6 and E10 xerogel showed 3D network, in which rigid (E6) and flexible (E10) fibers with the width of 0.5-2 $\mu \mathrm{m}$ were observed, while the concentrated solution of $\mathbf{E 5}$ consists of flat ribbons 2.7-3.0 $\mu \mathrm{m}$ wide (Fig. S3 $\dagger$ ). The formation of fibers or ribbons indicates that the self-assembly is driven by strong directional intermolecular interactions.

The rheological properties of the E6 and E10 gel were shown in Fig. S4. $\dagger$ The frequency sweep experiment (Fig. S4b and $d \dagger$ ) of the gel reveals that $G^{\prime}>G^{\prime \prime}$ and is independent of the frequency in a wide frequency region, indicating the gel nature of the sample. Stress sweep experiments (Fig. S4a and c $\dagger$ ) of the gel indicate that the $G^{\prime}$ and $G^{\prime \prime}$ cross each other at an oscillator stress of $10 \mathrm{~Pa}$, indicating the breaking of the gel to a sol state.

As shown in Fig. 2, FTIR spectroscopy of the E6 xerogel from DMF showed hydrogen-bonded $\mathrm{N}-\mathrm{H}$ stretching vibrations at around $3280 \mathrm{~cm}^{-1}$, free $\mathrm{C}=\mathrm{O}$ at around 1701 and hydrogen-

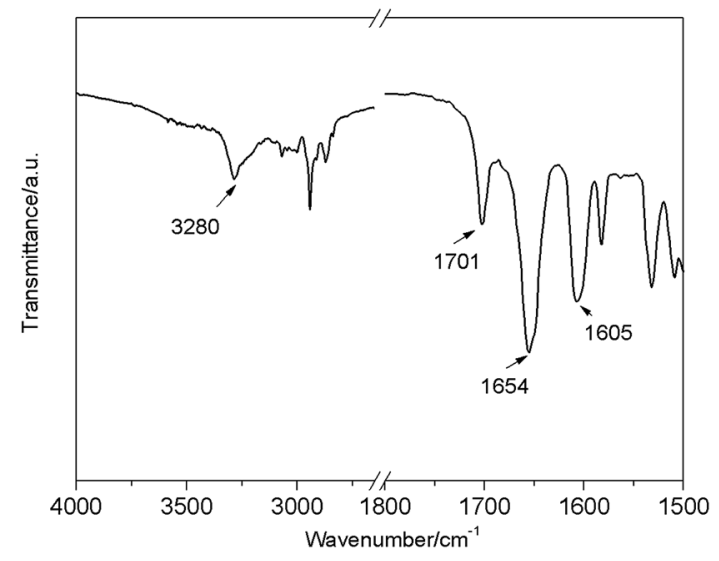

Fig. 2 FTIR spectrum of E6 xerogel $\left(8 \mathrm{mg} \mathrm{mL}^{-1}\right)$ in DMF.
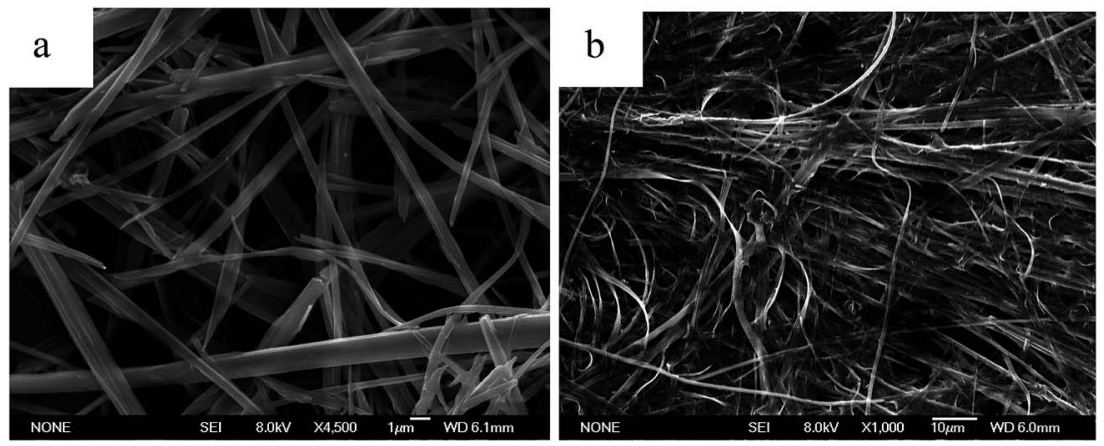

Fig. 1 SEM images of (a) E6 xerogels $\left(8 \mathrm{mg} \mathrm{mL}^{-1}\right.$ ); (b) E10 xerogels (11.5 mg mL ${ }^{-1}$ ) in DMF. 
bonded $\mathrm{C}=\mathrm{O}$ at around $1654 \mathrm{~cm}^{-1}$, indicating that the $\mathrm{N}-\mathrm{H}$ groups were mostly associated with $\mathrm{C}=\mathrm{O}$ groups via $\mathrm{N}-\mathrm{H} \cdots \mathrm{O}=$ $\mathrm{C}$ hydrogen bonding in the xerogel. ${ }^{18}$

In order to get more structural information, the xerogels were subjected to powder X-ray diffraction. As shown in Fig. 3, the XRD pattern of the E6 DMF xerogel exhibited sharp peaks in the lower-angle region with the $d$-spacings of $35.3 \mathrm{~nm}, 17.9 \mathrm{~nm}$ and $11.6 \mathrm{~nm}$, respectively, illustrating that a lamellar organization with the interlayer distance of $3.53 \mathrm{~nm}$ in the gel phase, which is slightly shorter than the calculated molecular length $(l$ $=3.68 \mathrm{~nm}$ ) of the most extended conformation, while it is same as that of $\mathrm{SmA}_{1}$ mesophase of E6. ${ }^{16}$ In the large angle range, a peak around $2 \theta=25.1^{\circ}(0.35 \mathrm{~nm})$ is characteristic of a typical $\pi-\pi$ stacking distance. ${ }^{17,19}$

\subsection{Photo-responsive properties}

As shown in Fig. 4, when the gel of E6 was exposed to UV light irradiation, the gel collapsed gradually and finally precipitates were observed. But this state did not change upon photoirradiation by visible light irradiation, and the gel phase could not be restored by heating.

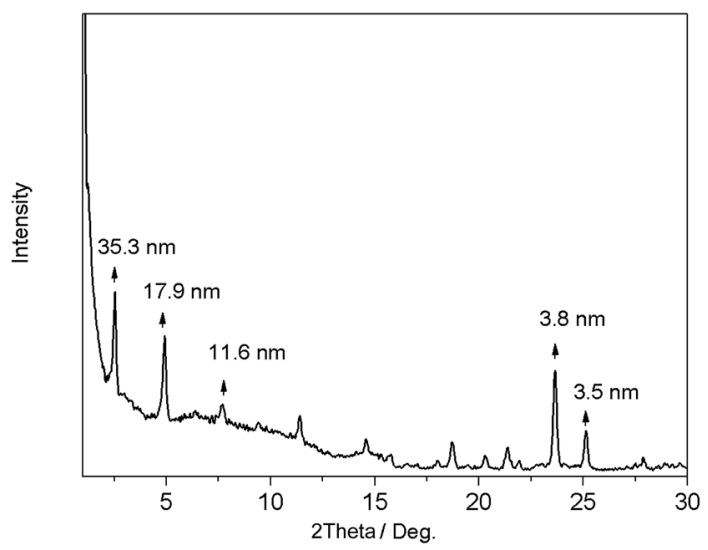

Fig. 3 X-Ray diffraction pattern of xerogel from E6 $\left(8 \mathrm{mg} \mathrm{mL}^{-1}\right)$ in DMF.

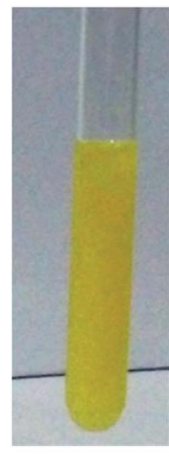

a

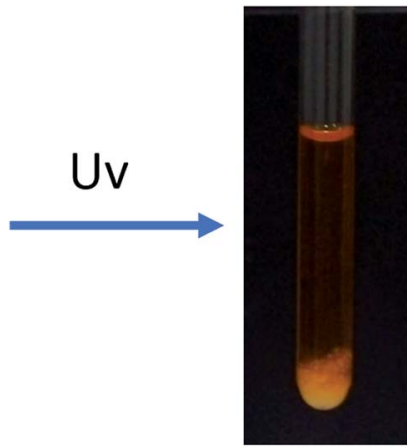

b
Fig. 4 Photographs of the DMF gel of E6 $\left(8.0 \mathrm{mg} \mathrm{mL}^{-1}\right)$ before (a) and after (b) UV light irradiation for $9 \mathrm{~h}$.
The UV light irradiation also caused the morphology change of the E6 gel. Compared to the fibrous aggregates of the xerogel in DMF (Fig. 1a), SEM image of the precipitates after UV light irradiation showed some fibers adhered some globular aggregates with diameters of 1-2 $\mu \mathrm{m}$ (Fig. 5a), whereas the cast film of the solution (developed from the gel in DMF under the UV light irradiation) showed globular aggregates, no fibers (Fig. 5b). The SEM image of the cast film of the solution after visible light irradiation on the basis of UV irradiation exhibited some globular aggregates adhered with each other (Fig. 5c).

This phase transition can be further confirmed by monitoring the UV-vis spectroscopy evolution of E6 solution in DMF $\left(1 \times 10^{-3} \mathrm{~mol} \mathrm{~L}^{-1}\right)$. The UV-vis spectroscopy (Fig. 6a) showed the typical change, the intensity of the $\pi-\pi *$ absorption peak of the trans-azobenzene moieties at $358 \mathrm{~nm}$ decreased with the UV light irradiation time, while that of the $n-\pi^{*}$ absorption peak of the cis-azobenzene at $448.5 \mathrm{~nm}$ increased concomitantly, indicating that photoinduced trans-cis isomerization took place and eventually brought about the gel-precipitate transition. Fig. S9† showed the reversibility in the photoisomerization by alternate irradiation of UV and visible light. The conversion efficiency of cis-azobenzene reached $\mathrm{ca} .87 \%$ at the photo-stationary state within $18 \mathrm{~s}$, estimated from the UV-vis absorption spectra (Fig. 6a), whereas the trans-azobenzene only can be recovered ca. 51\% at the photo-stationary state within $9 \mathrm{~s}$ (Fig. 6b). The trans-azobenzene cannot be all recovered was also confirmed by the ${ }^{1} \mathrm{H}$-NMR under irradiation by $450 \mathrm{~nm}$ visible light (Fig. S10c $\dagger$ ), but the trans-azobenzene can be recovered by heating (Fig. S10d $\dagger$ ) or place in darkness enough time after UV or visible light irradiation (Fig. S11†).

The FTIR spectrum of $\mathbf{E 6}$ in the precipitate (developed from the DMF gel under the UV irradiation) (Fig. 7a) showed characteristic bands of $\mathrm{N}-\mathrm{H}$ stretching modes of amide groups at $3240 \mathrm{~cm}^{-1}$, which is $40 \mathrm{~cm}^{-1}$ shorter than that in the gel state. In addition, the $\mathrm{C}=\mathrm{O}$ stretching vibration shifted from 1701 $\mathrm{cm}^{-1}$ and $1654 \mathrm{~cm}^{-1}$ (gel state) to $1654 \mathrm{~cm}^{-1}$ (precipitate). It is obviously that the intermolecular hydrogen bonding between $\mathrm{N}-\mathrm{H}$ and $\mathrm{C}=\mathrm{O}$ in the precipitate was stronger than that in gel state (Fig. 7b).

Combining the above results, we proposed a possible mechanism of photoinduced gel-precipitation change. E6 molecules in the gel state are dominantly in the trans-conformation, which self-assembled to layered aggregation to form the stable gel, and the main driving forces for gelation were intermolecular hydrogen bonding between the hydrazide groups and $\pi-\pi$ interactions between the azobenzene groups. Meanwhile there exists the equilibrium among the assembled fibrous network and the dissolved small assemblies and the molecularly dispersed trans-En. Irradiation of the gel by UV light firstly leads to trans-cis isomerization of the azobenzene units in the dissolved assemblies and the molecularly dispersed trans$\mathbf{E n}$. In the cis-isomers the dipole moment value increases, which improves the solubility of the E6 in DMF (polar solvent). With the increase of irradiation time, a certain amount of transisomers in fiber of organogel also turns into cis-isomers and then dissolves, thus the concentration of cis-isomers increases and further globular aggregates form. Meanwhile, the rest of 

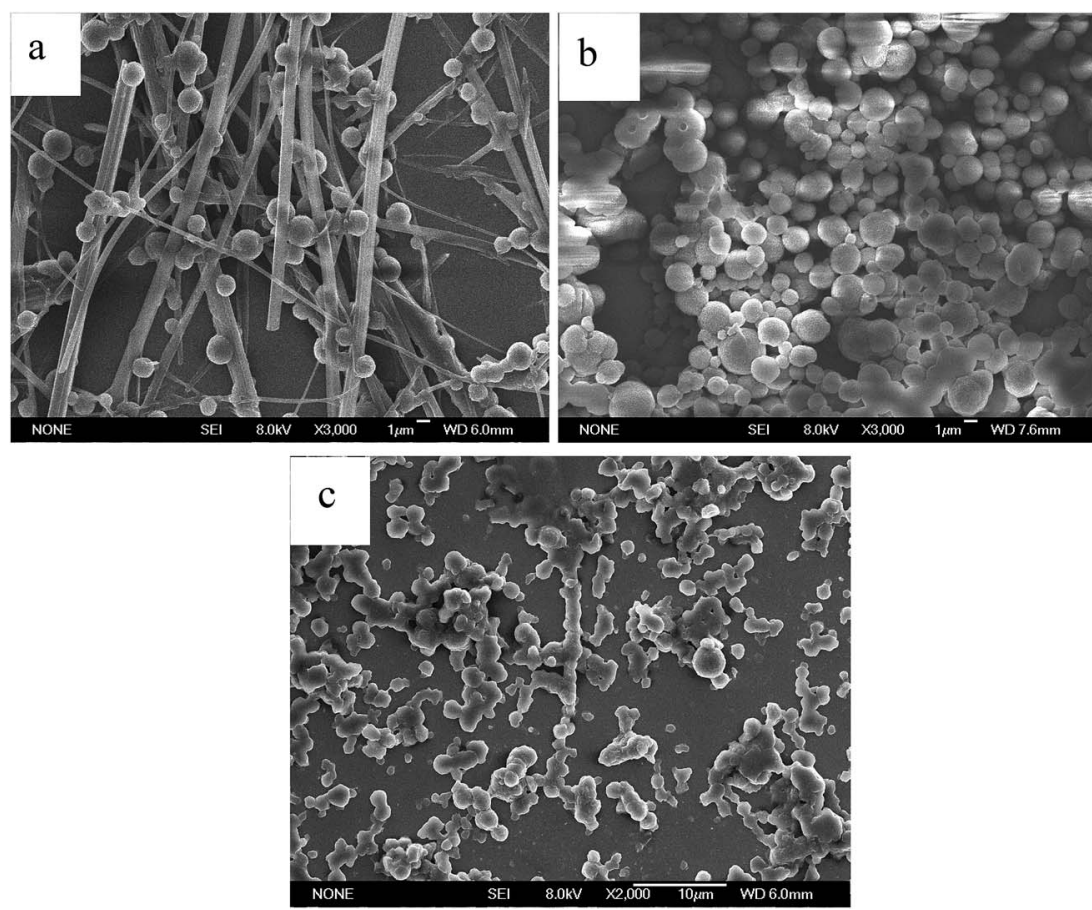

Fig. 5 SEM images of E6 (8 $\left.\mathrm{mg} \mathrm{mL}^{-1}\right)$ : (a) the precipitate and (b) the cast film of the solution (developed from the gel in DMF under the UV light irradiation); (c) the cast film of the solution after visible light irradiation on the basis of UV light irradiation.
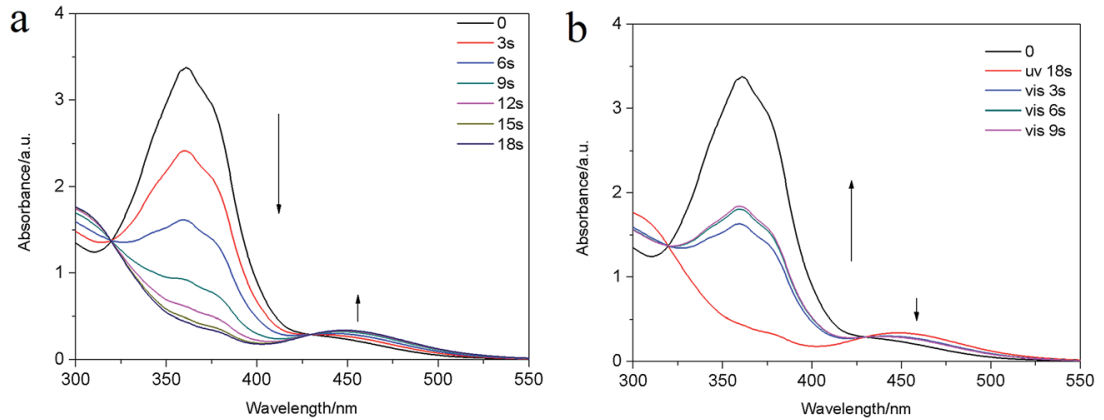

Fig. 6 UV-vis spectra of E6 solution in DMF $\left(1 \times 10^{-3} \mathrm{~mol} \mathrm{~L}^{-1}\right)(\mathrm{a})$ under UV light irradiation for $0-18 \mathrm{~s}$; (b) under visible light irradiation for $0-9 \mathrm{~s}$.

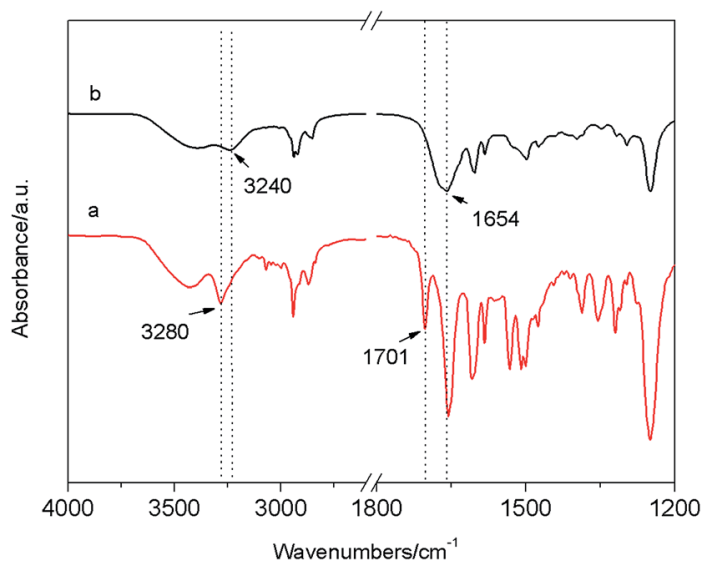

Fig. 7 FTIR spectra of (a) xerogel of E6 in DMF; (b) the precipitate developed from the gel in DMF under the irradiation of $365 \mathrm{~nm}$ UV light for $9 \mathrm{~h}$. fiber of trans-isomers in original organogel cannot support the large volume of organic liquid, so results in the organogel disintegrating and some fiber of trans-isomers precipitated out simultaneously.

\subsection{Anion responsive properties}

The use of these low molecular weight organogels as sensors for various anions $\left(\mathrm{F}^{-}, \mathrm{Cl}^{-}, \mathrm{Br}^{-}, \mathrm{I}^{-}, \mathrm{AcO}^{-}\right.$, as $\left[\mathrm{Bu}_{4} \mathrm{~N}\right]^{+}$salt) was examined in DMF. The presence of $\mathrm{F}^{-}$and $\mathrm{AcO}^{-}$not only changes the color of the systems, but also disrupts the preformed gel into a solution through slow diffusion of the anion, while gel remained upon addition of the other halide anions (Fig. 8). The absorption spectra of E6 in DMF (Fig. 9) in the presence of various anions showed intense variation upon the addition of $\mathrm{F}^{-}$and $\mathrm{AcO}^{-}$at room temperature. The new absorption bands at $451 \mathrm{~nm}$ are responsible for vivid color changes. 

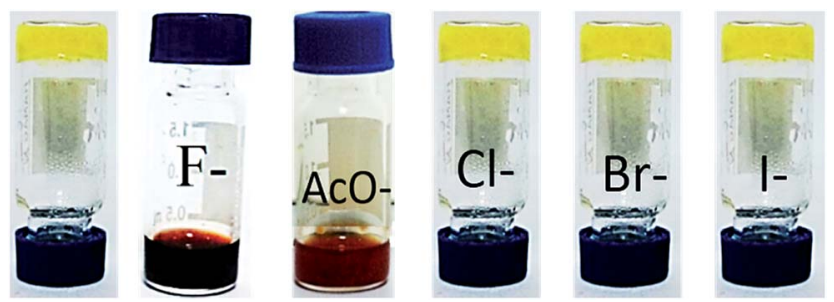

Fig. 8 Photograph of $E 6$ organogels $\left(8 \mathrm{mg} \mathrm{mL}^{-1}\right)$ upon adding of 10 equiv of various anions in DMF, from left to right: none, $\mathrm{F}^{-}, \mathrm{AcO}^{-}, \mathrm{Cl}^{-}, \mathrm{Br}^{-}, \mathrm{I}^{-}$.

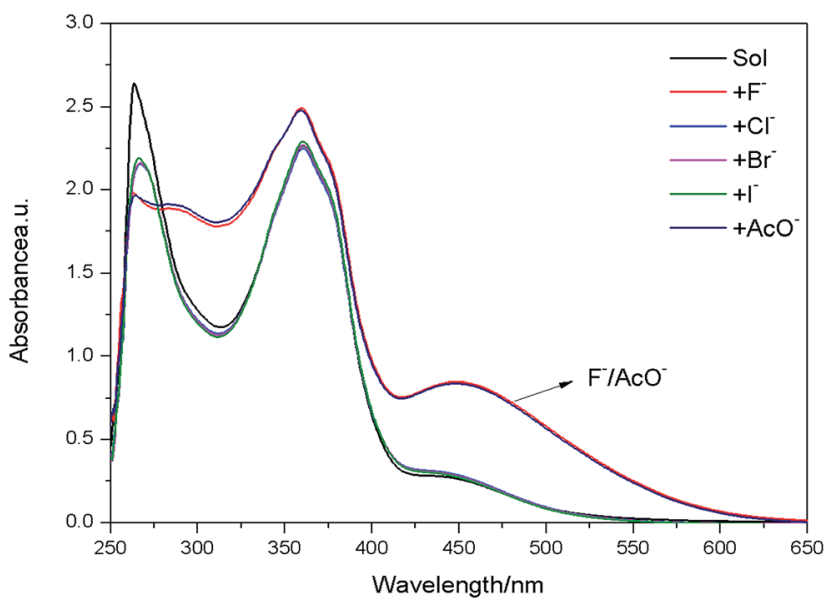

Fig. 9 UV-vis spectra of E6 $\left(1 \times 10^{-4} \mathrm{~mol} \mathrm{~L}^{-1}\right)$ in DMF upon addition of 10 equiv. of various anions $\left(\mathrm{F}^{-}, \mathrm{Cl}^{-}, \mathrm{Br}^{-}, \mathrm{I}^{-}, \mathrm{AcO}^{-}\right)$.

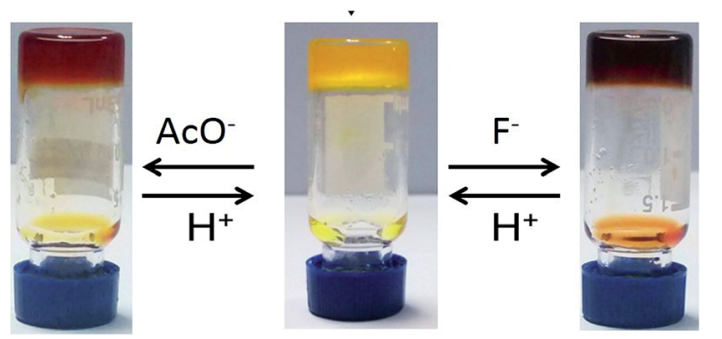

Fig. 10 Reversible gel-gel color transition of the two-components gel of 4-poxd-B8 and E5 (the molar ratio $1: 1$ ) in $\mathrm{DMSO}$ triggered by $\mathrm{F}^{-}$and $\mathrm{AcO}^{-}$.
The evidence for the anion-responsive mechanism was obtained from ${ }^{1} \mathrm{H}$ NMR experiments in DMSO- $d_{6}$ in Fig. S17, $\dagger$ the addition of 5 equiv. $\mathrm{F}^{-}$resulted in the disappearance of the signals at $10.46 \mathrm{ppm}$ and $10.64 \mathrm{ppm}$ of the NH protons, and the appearance of a weak signal at $\delta=10.44 \mathrm{ppm}$, indicating the formation of $\mathrm{N}-\mathrm{H} \cdots \mathrm{F}^{-}$hydrogen bond, simultaneously, a new weak signal appeared at $\delta=15.71 \mathrm{ppm}$, which implied the formation of a stable bifluoride hydrogen-bonding self complex $\left(\mathrm{HF}_{2}{ }^{-}\right)^{20-22}$ and the occurrence of bifluoride points to the deprotonation of either the $\mathrm{N}-\mathrm{H}$ group. After addition of 3 equiv. of $\mathrm{AcO}^{-}$ions, the $\mathrm{NH}$ signal disappeared, suggesting that only a hydrogen-bond complex $[\mathbf{E n} \cdot \mathrm{AcO}]^{-}$is observed in Fig. S18. $\dagger$

In addition, the gel-gel colorimetrical sensor can be obtained through two-component organogel based on E5 and 4poxd-B8 gelator in the Fig. 10 (the molar ratio $1: 1$, the molecular structure of 4-poxd-B8 was shown in Fig. $\left.\mathrm{S} 19 \uparrow^{-23,24}\right)$. As shown in Fig. S20, S21, S23 and S24, $\dagger$ the UV-vis and ${ }^{1} \mathrm{H}$ NMR spectra indicate that there is no interaction between the 4-poxd$\mathbf{B 8}$ and E5, as well as the 4-poxd-B8 and $\mathrm{F}^{-}$. The presence of $\mathrm{F}^{-}$ can not disrupt the preformed gel into a solution through slow diffusion of the $\mathrm{F}^{-}$, only can change the color of the twocomponent organogel (Fig. 10). The $\mathrm{F}^{-}$only can interact with $\mathbf{E 5}$, the role of the 4-poxd-B8 is to form 3D cross-linking network by self-assembling to support the solvent to form organogel and keep the organogel without disassembly in the presence of $\mathrm{F}^{-}$, which is in agreement with the morphology as shown in Fig. S22. $\dagger$

\section{4 $\mathrm{pH}$ responsive properties}

Similar to the $\mathrm{F}^{-}$response, reversible gel-sol transition induced by deprotonation and protonation steps by the addition of a base and an acid, respectively. Upon addition of 10 equiv. solid $\mathrm{NaOH}$ onto the top of the En DMF gel at room temperature, a thin layer of black solution immediately appeared at the upper part. As time passed, all the yellow gel transferred into black solution through slow diffusion of the $\mathrm{NaOH}$ (Fig. S25b $\dagger$ ). When the $\mathrm{HCl}$ was added into the black solution formed by the $\mathrm{NaOH}$ disintegrated gel, a new organogel formed again (Fig.S25c $\dagger$ ). The UV-vis spectroscopic (Fig. 11) and ${ }^{1} \mathrm{H}$ NMR titration
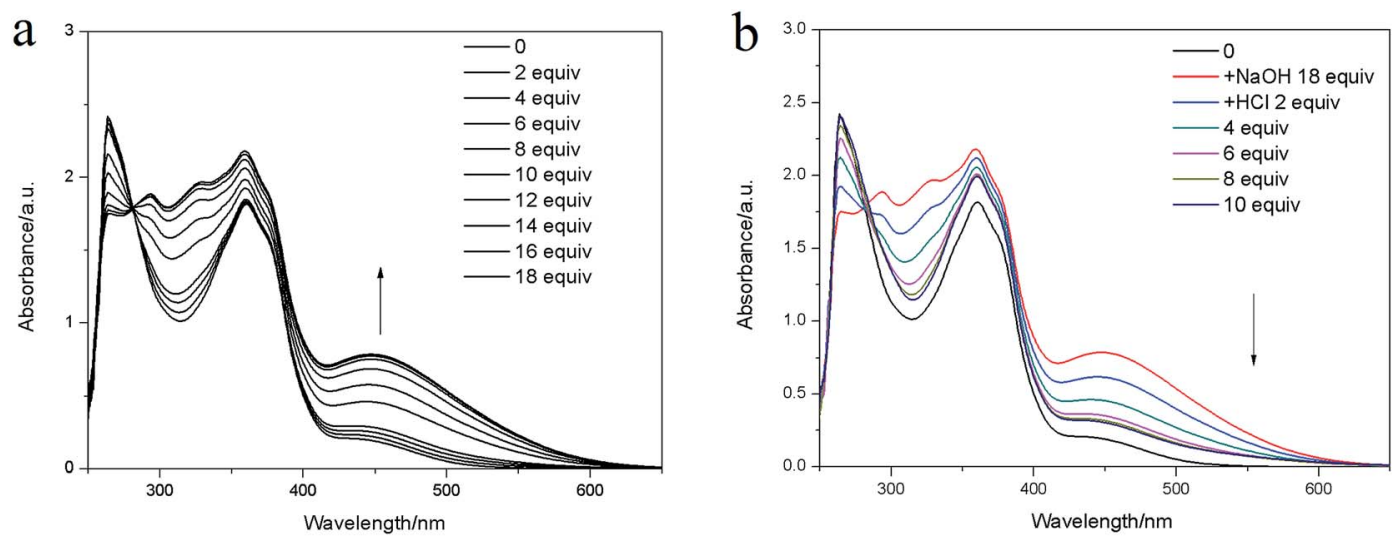

Fig. 11 UV-vis absorption spectra of E6 in the presence of (a) $\mathrm{NaOH}\left(0-18\right.$ equiv.); (b) $\mathrm{HCl}$ in DMF $\left(1 \times 10^{-4} \mathrm{~mol} \mathrm{~L}^{-1}\right)$. 
experiments (Fig. S26†) also confirmed the pH-responsive phenomenon..$^{7-9,25}$

\section{Conclusion}

In conclusion, the gelation behaviors of $\mathbf{E n}$ were studied. It was maybe due to the effect of the different molecular shape of En with the odd or even numbered central spacer, E6 and E10 could form stable organogel in DMF, but no gelation is observed for compound E5. The organogels exhibited multiple stimuliresponsive behaviors upon exposure to a number of environmental stimuli including temperature, light, anion and $\mathrm{pH}$. Upon irradiation with UV light, the organogels showed photoinduced gel-to-precipitate transition and morphological changed from fibrous to globular aggregates. Upon addition of anion $\left(\mathrm{F}^{-}\right.$ and $\mathrm{AcO}^{-}$) or base $(\mathrm{NaOH})$, the gel can show both color change and gel-sol transition. The results of these studies can further understand the structure-property relationships of LMOGs.

\section{Acknowledgements}

This work was supported by the National Natural Science Foundation of China (21072076), the Project of Science and Technology Development Plan of Jilin Province (20140414020GH) and Project 985-Automotive Engineering of Jilin University.

\section{References}

1 J. M. Lehn, Science, 1993, 260, 1762-1763.

2 J. M. Lehn, Supramolecular chemistry: concepts and perspectives, Wiley-VCH, Weinheim, 1995.

3 M. George and R. G. Weiss, Acc. Chem. Res., 2006, 39, 489497.

4 P. Terech and R. G. Weiss, Chem. Rev., 1997, 97, 3133-3160. 5 C. T. Chen, C. H. Chen and T. G. Ong, J. Am. Chem. Soc., 2013, 135, 5294.

6 M. Moriyama, N. Mizoshita, T. Yokota, K. Kishimoto and T. Kato, Adv. Mater., 2003, 15, 1335.
7 D. Y. Jeon, W. J. Yoo, S. H. Shin, et al., Journal of Sensor Science and Technology, 2012, 21(3), 223-228.

8 S. Islam, N. Bidin, S. Riaz, et al., Sens. Actuators, A, 2016, 238, 8-18.

9 K. Kimura, S. Yajima, H. Takase, et al., Anal. Chem., 2001, 73(7), 1605-1609.

10 T. Naota and H. Koori, J. Am. Chem. Soc., 2005, 127, 93249325.

11 G. Cravotto and P. Cintas, Chem. Soc. Rev., 2009, 38, 26842697.

12 K. Kimura, S. Yajima, H. Takase, et al., Anal. Chem., 2001, 73(7), 1605-1609.

13 S. H. Lee, J. Sumranjit, P. Tongkate, et al., Electrochim. Acta, 2014, 123, 198-204.

14 N. M. Sangeetha and U. Maitra, Chem. Soc. Rev., 2005, 34, 821-836.

15 C. T. Imrie, Struct. Bonding, 1999, 95, 149-192.

16 B. L. Bai, H. T. Wang, P. Zhang, S. N. Qu, F. Li, Z. X. Yu, B. Long and M. Li, Liq. Cryst., 2008, 35, 793-798.

17 B. L. Bai, M. G. Zhang, J. Wei, H. Y. Yan, H. T. Wang, Y. Q. Wu and M. Li, Tetrahedron, 2016, 72, 5363-5368.

18 P. I. Harris and D. Chapman, Biopolymers, 1995, 37, 251-263.

19 B. L. Bai, X. Y. Mao, J. Wei, Z. H. Wei, H. T. Wang and M. Li, Sens. Actuators, B, 2015, 211, 268-274.

20 Y. Zhang and S. Jiang, Org. Biomol. Chem., 2012, 10(34), 6973-6979.

21 L. Wang, W. Wei, Y. Guo, et al., Spectrochim. Acta, Part A, 2011, 78(2), 726-731.

22 J. W. Liu, Y. Yang, C. F. Chen, et al., Langmuir, 2010, 26(11), 9040-9044.

23 C. X. Zhao, H. T. Wang, X. Ran, B. L. Bai, Y. Zhang and M. Li, Chin. J. Chem., 2012, 30, 785-790.

24 C. X. Zhao, H. T. Wang, B. L. Bai, S. N. Qu, J. X. Song, X. Ran, Y. Zhang and M. Li, New J. Chem., 2013, 37, 1454-1460.

25 T. A. Khattab, B. D. B. Tiu, S. Adas, S. D. Bunge and R. C. Advincula, Dyes Pigm., 2016, 130, 327-336. 